\title{
Vertical Flux Profiles of Particulate Material in the Sea Off Sanriku
}

\author{
H. Sasaki and S. Nishizawa \\ Laboratory of Oceanography, Tohoku University, Sendai, 980 Japan
}

\begin{abstract}
Sinking particulate material was collected directly using a particle collector system in the sea area off Sanriku (Japan) in June 1977 and May 1978. A series of collectors were set for a day at the depth range of $50-500 \mathrm{~m}$ along a suspension rope hung from a surface buoy system. Many particles collected were visible to the naked eye; microscopic observations revealed that more than $90 \%$ of the particles above $125 \mathrm{~km}$ in diameter were either fresh fecal pellets of zooplankton or disintegrated loose clumps of possible fecal origın. These particles contained many skeletal remains, e. g. of diatoms. The maximum vertical flux of the sinking particles obtained in 1978 was $418 \mathrm{mg} \mathrm{C} \mathrm{m}^{-2} \mathrm{~d}^{-1}$ at $100 \mathrm{~m}$. This corresponds to about one third the daily primary production in the euphotic layer above. Below $100 \mathrm{~m}$, the downward flux gradually diminished to a level of $300 \mathrm{mg} \mathrm{C} \mathrm{m}^{-2} \mathrm{~d}^{-1}$ at $250 \mathrm{~m}$. A sharp decrease was found between 250 and $400 \mathrm{~m}$; the particulate flux was $28 \mathrm{mg} \mathrm{C} \mathrm{m}^{2} \mathrm{~d}^{-1}$ at $500 \mathrm{~m}$. This profile is very different from the vertical variation in particulate organic carbon simultaneously observed, the latte having a sharp peak at the depth of $50 \mathrm{~m}$. This indicates that sinking particles such as fecal pellets constitute most of the downward flux of materials and that the real flux of material is different - both in quantity and quality - from the conventional estimates based on observed carbon concentrations.
\end{abstract}

\section{INTRODUCTION}

Studies on marine suspended particles as a series of components in the material cycle of the ocean have been reviewed and discussed by Parsons (1963), Nishizawa $(1966,1969)$ and Riley (1970). The latter two authors, in particular, have emphasized the importance of aggregation processes of minute particles, including dissolved organic matter which form large conglomerates, because these were considered to be 'discrete centers' of biological activity in otherwise poverty-stricken oceanic environments. It is easy to suppose that these aggregates would sink fast and constitute a predominant fraction of the vertical flux of sinking materials even though they are relatively rare in occurrence compared to minute components. One of the major issues in biological oceanography in recent times involves the process of vertical transport of biological energy from the surface into the waters below. The main object of the present study is to investigate how much organic matter produced in the euphotic layer is removed to deeper layers, and what is the principal mechanism of removal.

The problems of the distribution of particulate organic matter in deep waters have long been debated.
Nishizawa (1969) and Iseki (1977) reviewed in detail the historical background of these controversies. Menzel and co-workers, in a series of papers (e. g. Menzel and Goering, 1966; Menzel, 1967), insisted on practical homogeneity in vertical as well as horizontal distributions of deep-water organic particles, while Riley et al. (1965) and Gordon (1970) observed significant seasonal and regional variations in the concentration of deep-water particles; these were claimed to reflect the variation of primary production in the shallow euphotic layer. Ichikawa and Nishizawa (1975) showed for a long meridional section in the East Pacific Ocean that the total amount of particulate material in the surface layer (0-200 $\mathrm{m}$ depth) was positively correlated with that in the entire water column below $200 \mathrm{~m}$. These observations indicate that (1) the downward transport of particles might be much quicker than thus far estimated (Riley, 1970; Smayda, 1970), and (2) the dominant fraction of vertical flux of particles does not consist of minute phytoplankton debris but is composed of a fewer larger ones.

Sinking large particles are difficult to collect with the conventional sampling bottle, primarily because they are rare in occurrence and heterogeneous in distribution in contrast to uniformly distributed minute 
particles. An inadequate sample size may miss them. Even if they are caught in a Van Dorn type sampler, they sink fast to the bottom of the sampler and would quite often escape from draining (Gardner, 1977). The best way to collect them seems to be to suspend an appropriate collector box in the water and wait for an adequate period of time. This way of sampling can also provide direct measurements of the vertical flux of particles. Various devices for the quantitative collection of sinking particles that have so far been described (e. g. Wiebe et al., 1976; Kimmel et al., 1977) follow this line. Iseki (1977) developed an in situ particle collector, and field operations were made using a series of the collectors and a modern mooring system in the Gulf of Alaska and the Bering Sea in 1975. Iseki found many large particles in his collectors, but the materials were clumped at the bottom of the collector making microscopic examination of discrete particles impossible. The present authors have developed a newly designed particle collector (PC), simple in construction and suitable for microscopic identification of collected material. Examinations were made by the use of both light and electron microscopes, and the vertical fluxes obtained were compared with conventional particulate organic carbon (POC) values observed simultaneously.

\section{MATERIALS AND METHODS}

PC experiments were conducted on 2 Cruises, KT77-8 (June 23 to July 1, 1977) and KT-78-7 (May 25 to $30,1978)$ of R. V. 'Tansei Maru' of the Sanriku coast of

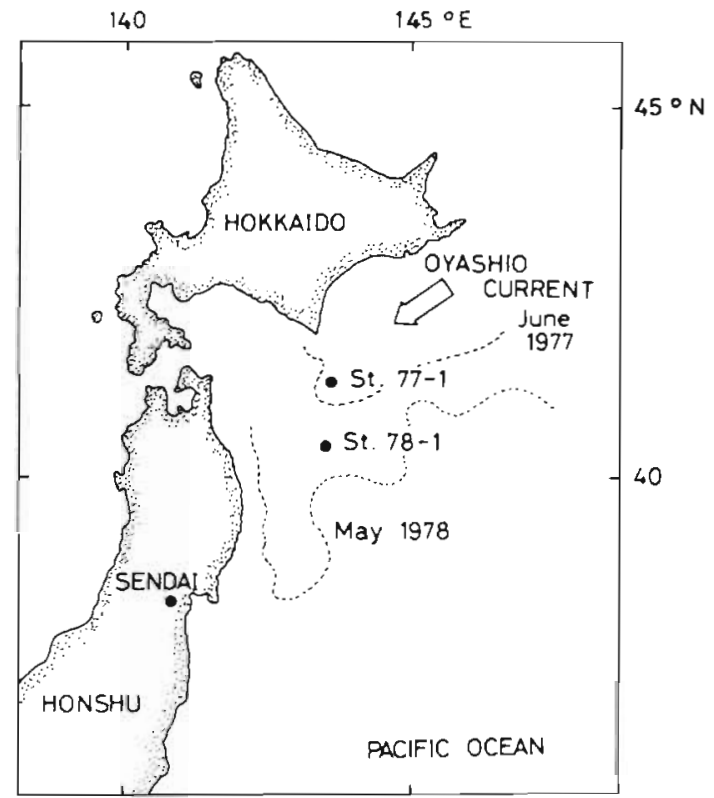

Fig. 1 Location of stations where PC experiments were conducted during the R.V 'Tansei Maru' cruises. $10^{\circ} \mathrm{C}$ isotherms in June 1977 and May 1978 are indicated northern Honshu, Japan. The operations were made at 2 stations, 1 per cruise. The stations were situated in the tongue-like southward extrusion of the cold Oyashio water penetrating into the transition water (Kawai, 1955; Fig. 1). Routine observations of temperature, salinity and dissolved oxygen using Nansen bottles, and water sampling using 25 l Van Dorn bottles for POC and chlorophyll pigments were also made at each station. Simultaneous horizontal tows with MTD nets (Motoda, 1971) consisting of Pylen No. 60 netting $(0.35 \mathrm{~mm}$ mesh) were made during the day and at night to collect zooplankton.

\section{Particle Collector (PC)}

The basic configuration of the PC used in this study is shown in Fig. 2. The cylindrical chamber has an effective diameter of $150 \mathrm{~mm}$ with a height of $500 \mathrm{~mm}$, and is made of PVC plastic. A honeycomb style baffle

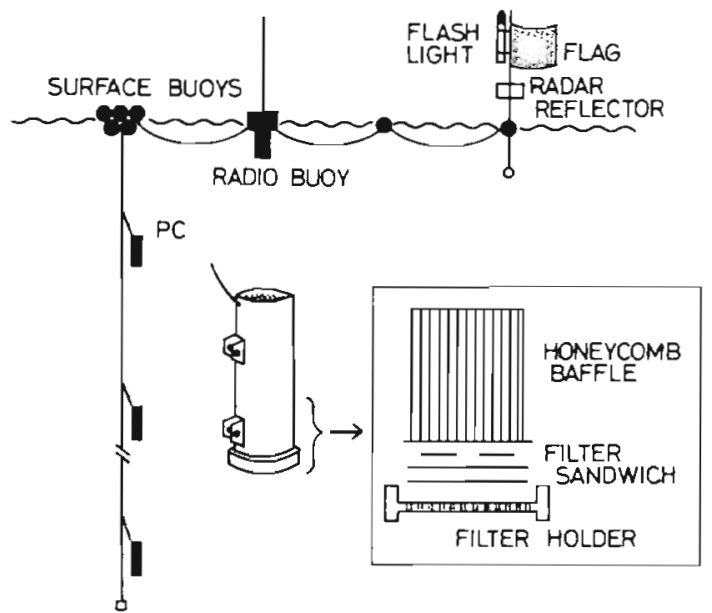

Fig. 2. PC suspension system used, PC assemblage and honeycomb baffle arrangement

which consists of a cluster of plastic tubes, $15 \mathrm{~mm}$ in diameter and $50 \mathrm{~mm}$ high, was set just above the filter sandwich to prevent aggregation of collected particles due to turbulent disturbance of water in the PC. Under the honeycomb, the filter sandwich composed of a Millipore filter $(150 \mathrm{~mm}$ in diameter, $0.8 \mu \mathrm{m}$ in pore size) and a filter pad as a cushion were placed on the filter holder. The filter holder was made to press the filter sandwich up by screwing the holder into the cylindrical chamber Two or 3 combusted GF/C Whatman glass fiber filters $(47 \mathrm{~mm}$ in diameter) were put separately on top of the Millipore filter When the PC was retrieved, sea water within the chamber was automatically drained out through the filter sandwich and a number of small holes (each about $2 \mathrm{~mm}$ in diameter) drilled in the bottom plate of the filter holder An 
Table 1 Data on stations where PC experiments were conducted

\begin{tabular}{|c|c|c|c|c|}
\hline $\begin{array}{l}\text { Station } \\
\text { number }\end{array}$ & Position & Date and duration & $\begin{array}{c}\text { Number of } \\
\text { layers sampled }\end{array}$ & $\begin{array}{l}\text { Maximum depth } \\
\text { sampled (m) }\end{array}$ \\
\hline St. $77-1$ & $41^{\prime} 16.3^{\prime} \mathrm{N} 14338.5^{\prime} \mathrm{E}$ & June $25-26,1977,1800-0600(12 \mathrm{~h})$ & 2 & 150 \\
\hline St. $77-1$ & & June $26,1977,0800-16.30(8.5 \mathrm{~h})$ & 2 & 150 \\
\hline St. $78-1$ & $40^{\circ} 28.5^{\prime} \mathrm{N} 14.3^{\circ} 28.1^{\prime} \mathrm{E}$ & May 26, 1978, 0930-1900 (9.5 h) & 8 & 500 \\
\hline St. $78-1$ & & May 26-27, 1978, 2100-0900 (12 h) & 8 & 500 \\
\hline
\end{tabular}

improved model of PC used on the KT-78-7 Cruise was practically identical with that used on the KT-77-8 Cruise in size, basic structure and sampling efficiency, but the honeycomb baffle was changed to a cluster of narrower plastic tubes, each $8 \mathrm{~mm}$ in diameter and $150 \mathrm{~mm}$ high.

A number of PCs were attached to the suspension rope (16 $\mathrm{mm}$ in diameter) and the entire assembly was hung from a free drifting surface buoy system, consisting of a series of surface buoys, a radio-buoy and flagbuoy with a radar reflector (Fig. 2). In 1977, 2 PCs also served as connectors between the 3 separate ropes, but in 1978 the new PCs were simply hung and tied to a single long rope. Just before immersing them, all the PC chambers were filled with seawater filtered through a net, $0.35 \mathrm{~mm}$ in mesh aperture. The collection periods were $8-12 \mathrm{~h}$ and the collections were made twice during the day and at night at each station. In 1977, 2 depths (50 and $150 \mathrm{~m}$ ) were sampled and in 1978,8 depths were sampled with a maximum depth of $500 \mathrm{~m}$ (Table 1).

\section{Laboratory Procedure}

After the PC system was retrieved and seawater inside the PC was filtered off, the cylindrical chamber and the filter holder of each PC were gently washed with a $3 \% \mathrm{NaCl}$ solution. Each filter was immediately refrigerated for later microscopy and analyses. Millipore filters with the particles sedimented were dried in a desiccator for more than a week after dehydration. Parts of the filter (ca $3 \mathrm{~cm}^{2}$ a piece and $10 \mathrm{~cm}^{2}$ in total) randomly selected were observed with a light microscope and a scanning electron microscope (SEM) for determination of size-frequency distribution and microstructure of collected material. One of the glass fiber filters with particles was analyzed for POC using an infrared analyzer (Strickland and Parsons, 1968) and the other for pigments by fluorometry (Nishizawa et al. 1971). Five l aliquots of Van Dorn samples filtered on board were analyzed for POC and 11 aliquots for chlorophyll pigments.

Experiences showed that the salinity of seawater inside the baffles, when measured immediately after retrieval, was very close to that in the water layer in which it was suspended while the salinity in the upper compartment was nearly identical to that of the surface water. Therefore, calculations of carbon and pigment fluxes were made under the assumption that the filtered sea water that initially filled a PC before lowering was completely displaced by the surrounding water during the suspension time and, while hauling, the water inside except for the honeycomb compartment was once again continuously displaced by waters surrounding the PC, so that when the PC was finally retrieved this volume was filled with the surface seawater and the honeycomb compartments with the water at the suspension depth. The particle contents in the 2 volume parts of the PC were calculated using observed POC values at respective depths and subtracted from the total amount of particles caught on the filter at the bottom of the PC. A possible contribution of sinking particles during lowering and retrieval time (less than 20 min each) was simply neglected.

\section{RESULTS}

\section{Hydrographic Backgrounds}

Vertical profiles of temperature, chlorophyll a and POC at St. 77-1 (KT-77-8 Cruise) and St. 78-1 (KT-78-7 Cruise) are given in Figs. 3 and 4 . These profiles pro-

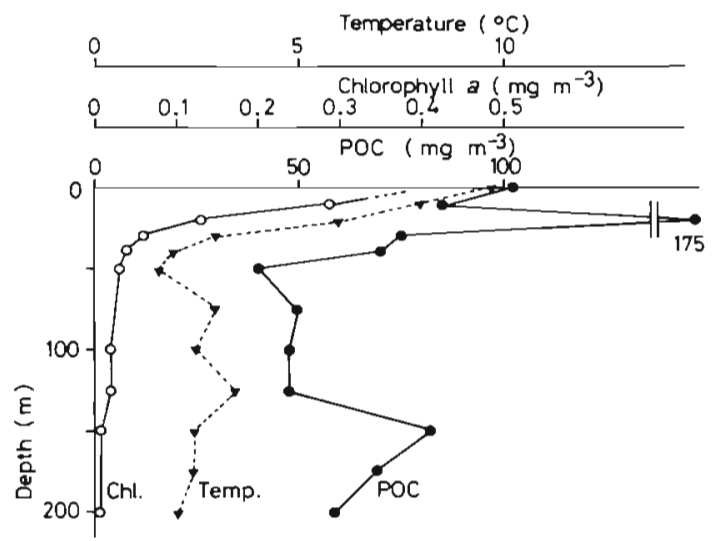

Fig. 3. Vertical profiles of temperature, chlorophyll $a$ and particulate organic carbon (POC) observed at Station 77-1 on June 25,1977 


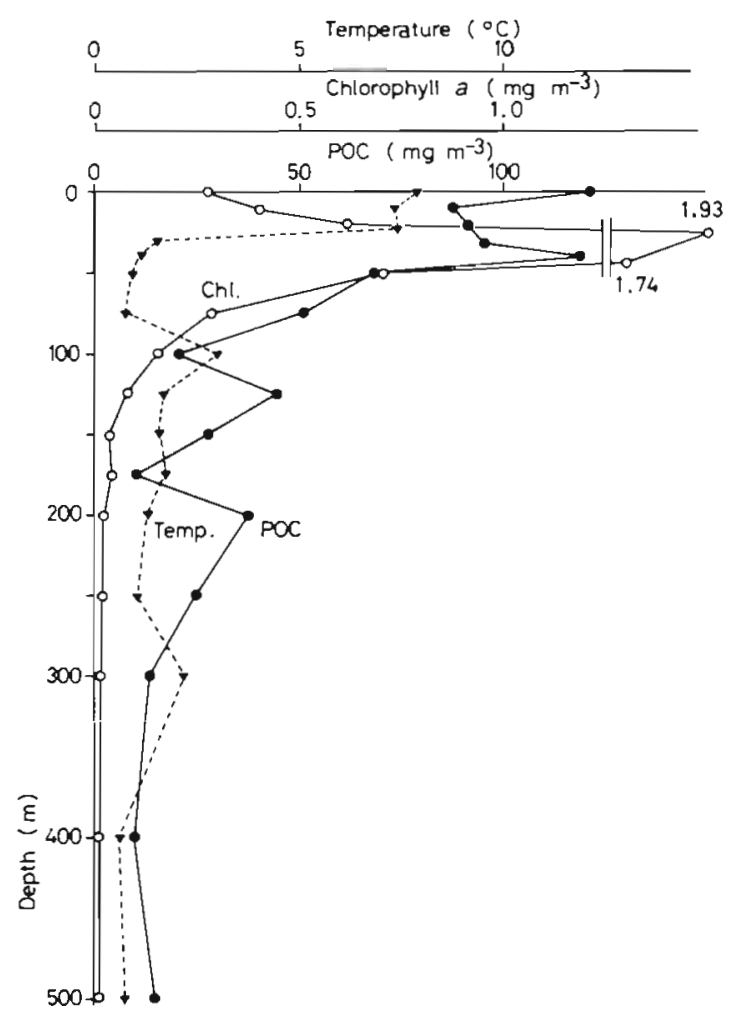

Fig. 4. Vertical profiles of temperature, chlorophyil a and POC observed at Station 78-1 on Mdy, 1978

vide the oceanographic backgrounds of the areas in which PC samples were taken. On both cruises, hydrographic profiles appeared to show typical characteristics of the boreal water dominated by the Oyashio water There were distinct maxima in both chlorophyll $a$ and POC in the shallow water layer slightly less than $50 \mathrm{~m}$ in depth accompanied by sharp negative gradients below

\section{Microscopic Observations of Collected Materials}

Microscopic photographs shown in Fig. 5 were obtained for the samples taken from Station 77-1. There were many discrete particles collected on the filters that were easily recognizable to the naked eye (Fig. 5a). Microscopic observations showed that fecal pellets, typical of zooplankton, were abundant on the filters (Fig. 5b). These pellets, greenish brown in color, looked fresh and little damaged mechanically. The majority of the large pellets were morphologically classified into 2 groups. One type was cylindrical, very Iong and slender. The average dimensions of these pellets were $700 \pm 200 \mu \mathrm{m}$ long and ca $30 \mu \mathrm{m}$ wide. These are probably feces voided by euphausiids; fairly dense populations of Euphausia pacifica were caught by the net tow at the station. The second type of fecal pellets was oval shaped. The ranges of length and width were $300 \pm 100 \mu \mathrm{m}$ and $50 \pm 20 \mu \mathrm{m}$ respectively The major producer of this type of pellets seemed to be copepods, particularly the dominant species Calanus plumchrus. Many amorphous particles were also found on the PC filters (Fig. 5c). Some of these particles were loose in structure and resembled degraded fecal pellets in appearance. They also contained many skeletal remains, so that the origin of these amorphous particles was assumed to be fecal pellets. Under the light microscope, a series of biogenic particles other than fecal materials were also found They were diatoms, foraminiferans, radiolarians and fragments of crustacean carcasses. These biogenic materials often mingled or coagulated with detrital particles

SEM observations showed that the surface of fecal pellets was partially covered by a continuous membrane which shielded the internal contents from the seawater outside (Figs. $5 \mathrm{~d}$ and e), and that euphausiid pellets primarily contained amorphous detrital materials, while calanoid pellets contained many skeletal remains of diatoms.

\section{Particle Size Distributions}

Small portions of filters with sediments were mounted onto glass slides and the maximum dimensions of all particles above $32 \mu \mathrm{m}$ were measured under a light microscope. First, the compositions of particles larger than $125 \mu \mathrm{m}$ in maximum dimension were morphologically scrutinized. They were classified into fecal pellets, 'fecal matter' (after Bishop et al., 1977), i.e. any loose clump of material possibly of fecal pellet origin, single plankton and fragments. The size spectra obtained (Fig. 6) show that the number of particles sharply decreases with increasing diameter. But the proportion of fecal materials (fecal pellets and fecal matter) to the total number of particles above $125 \mu \mathrm{m}$ in diameter increases gradually with increasing diameter. Particularly, large feces dominate in the size fractions larger than ca. $500 \mu \mathrm{m}$. For example, at the depth of $50 \mathrm{~m}$, the percentage contribution of fecal pellets was $21.5 \%$ in the size range $125-250 \mu \mathrm{m}$, $60-80 \%$ in the range $250-2000 \mu \mathrm{m}$, and up to $100 \%$ in the range above $2 \mathrm{~mm}$. The same contribution at the depth of $150 \mathrm{~m}$, was $22.4 \%$ in the range $125-250 \mu \mathrm{m}$, $60-90 \%$ in the range $250-2000 \mu \mathrm{m}$, and up to $100 \%$ in the range above $2 \mathrm{~mm}$. Average contributions of pellets to the total particles above $125 \mu \mathrm{m}$ were $48.0 \%$ and $50.8 \%$ in number respectively. The contributions of fecal materials including fecal matter were more than $90 \%$ at both depths.

All data of size spectrum for particles larger than 
$32 \mu \mathrm{m}$ again displayed the trend of rapidly decreasing frequency with increasing diameter. The size spectrum was converted to a plot of cumulative number $N$ (number of particles larger than a given diameter d) versus $d$ on a $\log$-log sheet (Fig. 7). The relation showed a relatively straight decrease of $N$ with increasing $d$, and the inclination $m$ was in a range of -1 to -3 . In the size ranges ca $50-125 \mu \mathrm{m}$ and larger than $500 \mu \mathrm{m}$ in diameter, the slopes were close to -3 . The intermediate range $(125-500 \mu \mathrm{m})$ had a low value
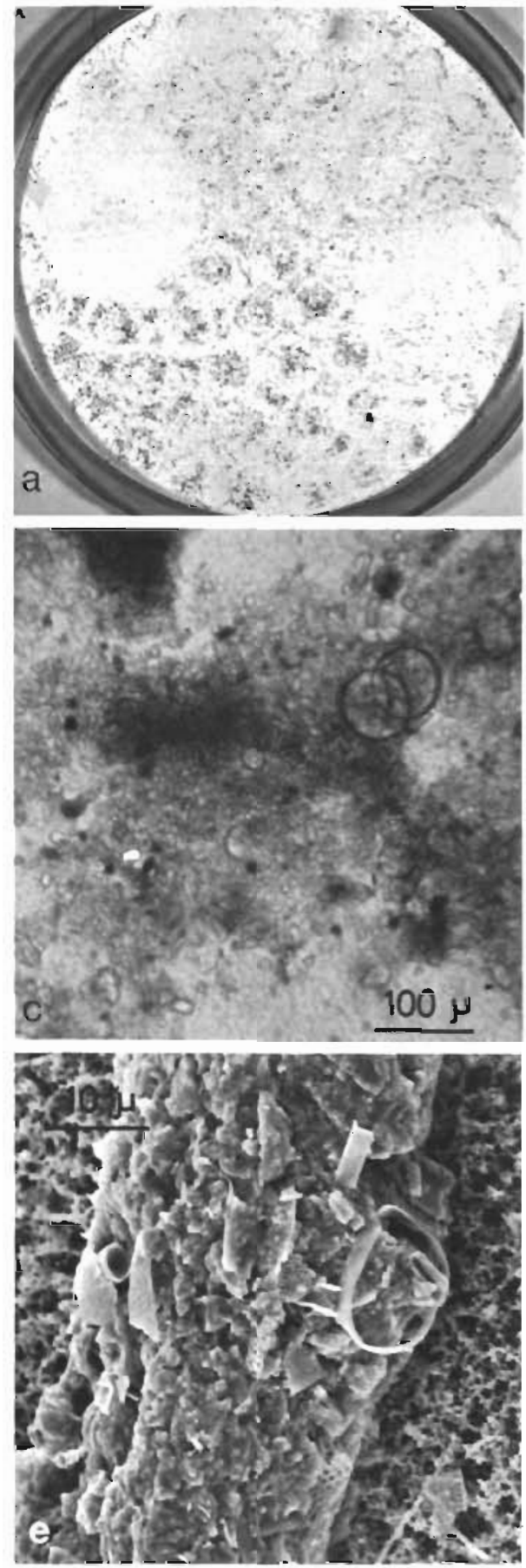

of $m$ around -1 Bader (1970) and McCave (1975) showed that the cumulative number $N$ of marine particles is expressed by a simple hyperbolic relation

$$
N=a d^{m i}(a=\text { constant })
$$

in a remarkable number of cases, and that the value of $m$ might vary with samples but the range was narrowly centered around -3 , an assumption which was also substantiated by Sheldon et al. (1972) for marine particles from various localities of the Pacific and the Atlan-
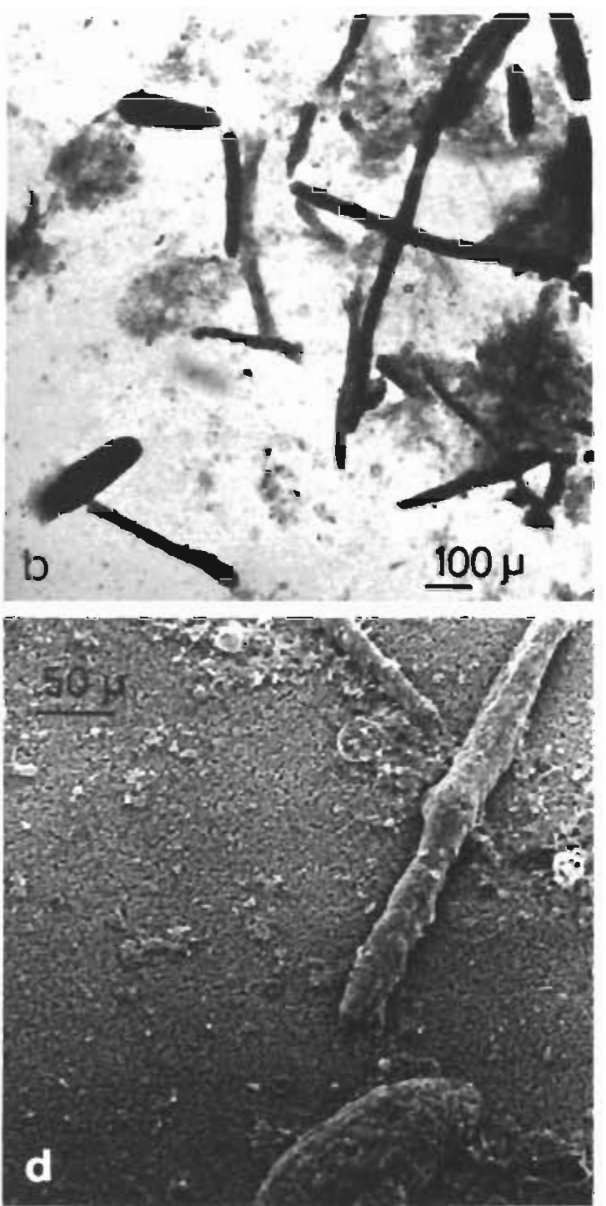

Fig. 5. (d) Particles sedimented on Millipore filter placed on the bottom of PC, suspended at $150 \mathrm{~m}$ depth at Station 77-1 on June $25-26,1977$; (b) fecal pellets and fecal matter; (c) degraded fecal pellet; (d) 2 types of fecal pellets (see text); (e) detail of one of the pellets in (d) 


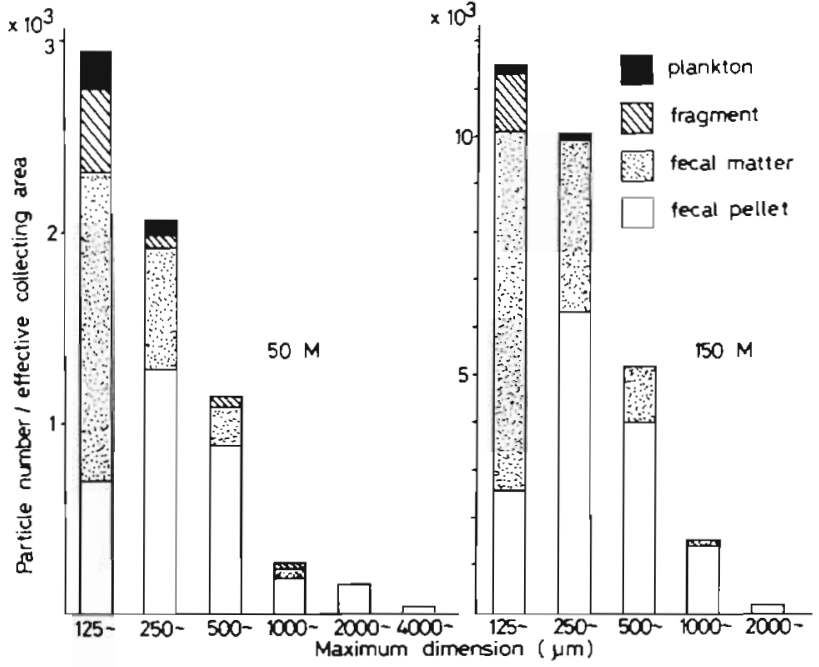

Fig. 6. Size spectra and composition of particles larger than $125 \mu \mathrm{m}$ (maximum dimension) collected using PC suspended at 50 and $150 \mathrm{~m}$ on June $25-26,1977$

tic Ocean using the electronic counting technique (Coulter Counter).

The results of this study seem to show that the hyperbolic relation can also be roughly applicable to the $\mathrm{PC}$ samples having a size range well over $1000 \mu \mathrm{m}$; the maximum size observed was $8 \mathrm{~mm}$. Thus the PC sample represents a part of the entire spectrum of marine particles as hypothesized by the workers cited above in the size range from ca. $500 \mu \mathrm{m}$ to several

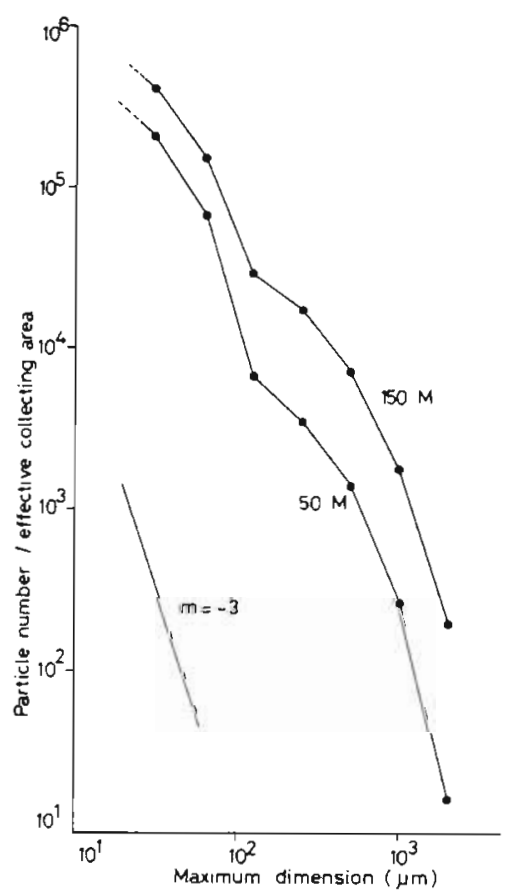

Fig. 7 Size-frequency distributions of particles collected using PC suspended at 50 and $150 \mathrm{~m}$ on June 25-26, 1977 Straight line: slope of -3 mm which is not covered by the conventional electronic counting. In the smaller size range, the PC sample tends to give a skewed picture of the spectrum suggesting that smaller particles tend to escape from being caught in the PC. The upper end of the size range is probably governed by the mouth area of the $\mathrm{PC}$ if the suspension time is fixed, and the lower end by the suspension time itself. The marked irregularity found in the size range $125-500 \mu \mathrm{m}$, however, indicates that the particles in this range are relatively low in occurrence. It is noticeable that the increase in $m$ of both curves in the size range from $125 \mu \mathrm{m}$ and upwards (Fig. 7) is concomitant with the simultaneous increase in fecal pellet proportion and decrease in fecal matter proportion of the collected materials (Fig. 6). Fecal matter was mostly a clump of degraded particles apparently loose in conglomeration and would have a lower sinking rate compared to a fresh fecal pellet of the same dimension. The decrease of $m$ in the size range below ca $50 \mu \mathrm{m}$ shows minor contribution of the small particles to the total flux although microscopic identifications of particles in this size range were not always successfully performed.

\section{Variation of Vertical Fluxes with Depth}

Chemical analyses for POC, chlorophyll a and pheopigments contained in PC samples and Van Dorn samples were summarized in Tables 2 and 3 . The data obtained using PCs are shown as the flux per square meter per day. The right-hand side of Table 2 shows the results of Van Dorn samples from respective depths. The organic carbon flux through the layer at $150 \mathrm{~m}$ at St. $77-1$ was $204 \mathrm{mg} \mathrm{C} \mathrm{m}^{-2} \mathrm{~d}^{-1}$ which is about four times larger than that through the layer at $50 \mathrm{~m}$ depth. The concentrations of suspended particles in surrounding waters as sampled by the use of Van Dorn bottles at both depths were 87 and $48 \mathrm{mg} \mathrm{C} \mathrm{m}^{-3}$ respectively. The chlorophyll a content was low in the $50 \mathrm{~m}$ Van Dorn sample and a trace of the pigment was still

Table 2. Comparison of chemical characteristics between PC samples and Van Dorn samples at Station 77-1 (tr.: trace, $<0.001)$

\begin{tabular}{|clcc|}
\hline $\begin{array}{c}\text { Depth } \\
(\mathrm{m})\end{array}$ & Analysis & $\begin{array}{c}\text { PC sample } \\
\left(\mathrm{mg} \mathrm{m} \mathrm{m}^{2} \mathrm{~d}\right)\end{array}$ & $\begin{array}{c}\text { Van Dorn } \\
\text { sample } \\
(\mathrm{mg} \mathrm{m})\end{array}$ \\
\hline \multirow{2}{*}{50} & POC & 45 & 48 \\
& chlorophyll a & $\mathrm{tr}$ & 0.025 \\
& pheopigments & 0.275 & 0.091 \\
& POC & 204 & 87 \\
& chlorophyll a & $\operatorname{tr}$ & 0.006 \\
& pheopigments & 0.821 & 0.066 \\
\hline
\end{tabular}


Table 3. Downward flux of POC, chlorophyll a and pheopigments estimated using $P C$ at Station 78-1

\begin{tabular}{|c|c|c|c|}
\hline $\begin{array}{l}\text { Dopth } \\
(\mathrm{m})\end{array}$ & $\begin{array}{c}\text { POC } \\
\left.\text { (meg m } m^{\prime} d^{\prime}{ }^{\prime}\right)\end{array}$ & $\begin{array}{l}\text { Chlorophylla } \\
\text { (mg no de }\end{array}$ & $\begin{array}{l}\text { Pheopigments } \\
\left(\text { (mg } m^{2} \mathrm{~d}^{1}\right)\end{array}$ \\
\hline 50 & 354 & 0.172 & 1090 \\
\hline 100 & 418 & 0.223 & 1.801 \\
\hline 150 & 395 & 0.080 & 1.156 \\
\hline 200 & 317 & 0.009 & 0.802 \\
\hline 250 & 350 & tr & 0.867 \\
\hline 300 & 233 & 11 & 0.512 \\
\hline 400 & 77 & tr & 0.22 .5 \\
\hline 500 & 28 & $\operatorname{tr}$ & 0.085 \\
\hline
\end{tabular}

observed at the depth of $150 \mathrm{~m}$. The PC samples, however, contained only a barely detectable amount of chlorophyll $a$ and a significantly high amount of pheopigments.

A fairly complete set of flux data was obtained from 8 layers taken at St. 78-1 (Fig. 8, Table 3). At the bottom of the upper mixed layer the observed flux was $354 \mathrm{mg} \mathrm{C} \mathrm{m}^{-2} \mathrm{~d}^{-1}$, and a marked maximum of $418 \mathrm{mg} \mathrm{C} \mathrm{m}^{-2} \mathrm{~d}^{-1}$ was found at the depth of $100 \mathrm{~m}$ Below this depth, downward fluxes gradually reduced to a level close to $300 \mathrm{mg} \mathrm{C} \mathrm{m} \mathrm{m}^{-2} \mathrm{~d}^{-1}$ in the depth range of $100-250 \mathrm{~m}$. A sharp decrease occurred between 250 and $400 \mathrm{~m}$ with a subsequent slow decrease down to a minimum of $28 \mathrm{mg} \mathrm{C} \mathrm{m} \mathrm{m}^{-2} \mathrm{~d}^{-1}$ at $500 \mathrm{~m}$. It is quite noticeable that the variation of vertical fluxes with depth (Fig. 8, right) differed greatly from the vertical profile of POC (Fig. 8, left). The most notable distinction between them was that the flux maximum occurred at $100 \mathrm{~m}$ while the concentration of POC had a distinct minimum at the same depth. The flux maxima of pigments at St. $78-1$ were also found at $100 \mathrm{~m}$ (Table 3), $60 \mathrm{~m}$ below the chlorophyll maximum layer. The pheopigments fluxes at depths less than $150 \mathrm{~m}$ were nearly one order of magnitude larger than those of the chlorophyll a at respective depths. Below $200 \mathrm{~m}$, the former fluxes were more than 2 orders of magnitude larger than the latter. The flux of chlorophyll a decreased sharply with depth and below $250 \mathrm{~m}$ it was undetectable. The flux of pheopigments, however, diminished gradually with depth and at the deepest layer observed it still measured $0.085 \mathrm{mg} \mathrm{m}^{2} \mathrm{~d}^{-1}$.

\section{DISCUSSION}

Many sophisticated designs have been developed for 'sediment traps' (e.g. Kirchner, 1975; Hakanson, 1976; Honjo, 1978; Staresinic et al., 1978). The PCs designed and used in this study are very simple in construction and also inexpensive. They are easy to handle, and suspension as well as retrieval of the system require only short ship time. This made any lid installment almost unnecessary because sample contamination in the honeycomb baffle, which may occur during retrieval, can be minimized if the system is kept suspended for a sufficiently long time. In the 2 cases discussed in this study we spent only 15 min for retrieval. The honeycomb baffle effectively prevents disturbing water movement in the bottom part of the chamber, and the collected particles resting upon the filter are preserved as a group of discrete particles which can easily be scrutinized microscopically. For a practical check of contamination we lower a PC down to any depth and then pull it up immediately. Preliminary tests show that the values obtained were slightly less than $10 \mathrm{mg} \mathrm{C} \mathrm{m}^{-2}$ (uncorrected) for one dip down to $2000 \mathrm{~m}$ in an oligotrophic sea; no large particles were visible on the filters. No similar check was made during the present cruises, but the deepest PC - suspended for half a day - brought back particles of $17.1 \mathrm{mg} \mathrm{C} \mathrm{m}^{-2}$. This figure could probably serve as a maximum blank value indicating external contamination that might occur during lowering and retrieval of

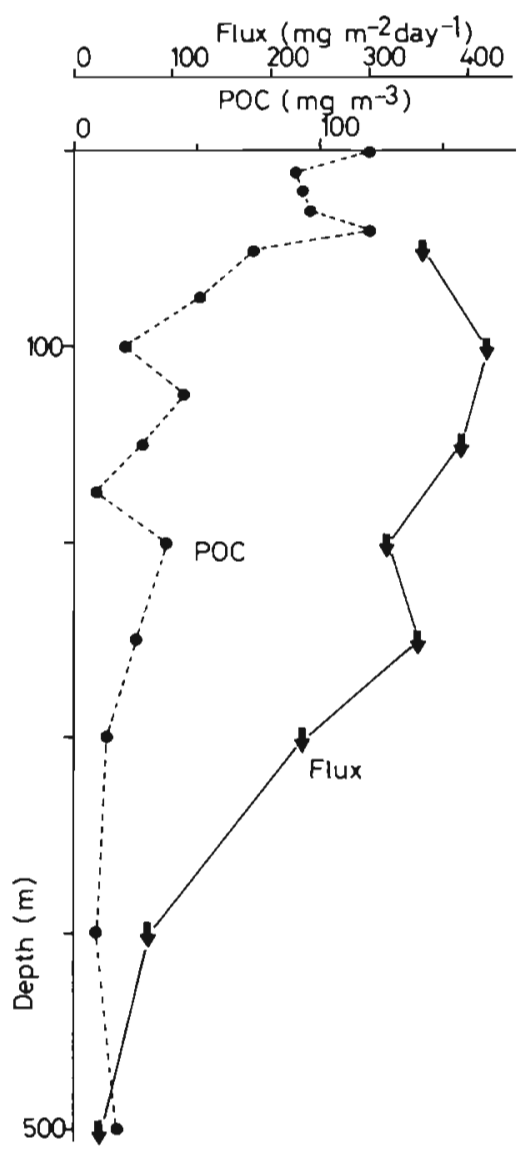

Fig. 8. Vertical variation of particulate organic carbon fluxes and vertical profile of POC concentrations, sampled at Station 78-1 on May 26-27, 1978 
the PC. Even if this value were subtracted, the entire situation will not be changed very much.

There is evidence that undigested carbonate and siliceous skeletal remains from phytoplankton food are important constituents of copepod fecal pellets (Schrader, 1971; Honjo, 1978; Honjo and Roman, 1978). Honjo (1976) suggested that the presence of suspended coccoliths in the deep water column, undersaturated with respect to calcium carbonate, could be explained by the accelerated and communal sinking of grazed coccospheres in zooplankter fecal pellets. It has been estimated that the sinking speed of fecal pellets ranges from $74-210 \mathrm{~m} \mathrm{~d}^{-1}$ for the copepod Acartia clausi (Smayda, 1969) and from 53-862 $\mathrm{m} \mathrm{d}^{-1}$ for euphausiid species (Fowler and Small, 1972). According to these data, fecal pellets, originating from the euphotic layer, are presumed to have sinking rates sufficiently rapid to arrive at the depth of $500 \mathrm{~m}$ within less than $10 \mathrm{~d}$. The membrane covering fecal pellets may play an important role in keeping the pellets intact during sinking (resistance to biodegradation) and in providing the particles with a high sinking speed (smooth surface area). These properties have been described for marine and fresh water fecal pellets (Honjo, 1976; Ferrante and Parker, 1977). Honjo and Roman (1978) showed that when fecal pellets were exposed to $5^{\circ} \mathrm{C}$ seawater in the laboratory, the surface membranes were kept intact for at least $20 \mathrm{~d}$. Sooner or later these pellets will either be consumed by coprophagous animals or sink further down. Ultimately, the membrane of an unconsumed pellet will be attacked by bacteria while it sinks through the water column, and finally be broken, resulting in the release of pellet contents into the surrounding water. The released contents will transform into amorphous loose clumps (fecal matter) or disperse into the water and cease to sink rapidly because of their lowered density or minute size. Individual diatom frustules collected in deep waters by $\mathrm{PC}$ may be derivatives of degraded fecal pellets; they are not considered to be transported by individual sinking processes directly from the euphotic layer. The high abundance of pheopigments and exceedingly low abundance of chlorophyll a in PC samples also strongly suggest that undigested materials containing degraded chlorophyll pigments are transferred rapidly to deeper layers in the form of fecal pellets and fecal matter.

Numerous measurements and estimates have been made of the sinking velocities of living and detrital organic particles (e. g. Riley, 1970; Smayda, 1970). Although there is still some uncertainty in determining in situ sinking rates of these particles, the information available suggests that a fairly wide range of sinking velocity is observed for individual particles (cf. Smayda, 1970), but the sinking velocity averaged with respect to in situ occurrence frequency of these particles tends to be lower than a few $\mathrm{m} \mathrm{d}^{-1}$ because of the well-known preponderance of small particles. Burns and Rosa (1980) recently showed for a fresh water suspension that the POC fluxes of particles in the size ranges $1-10 \mu \mathrm{m}, 10-64 \mu \mathrm{m}$ and $>64 \mu \mathrm{m}$ were about equal for each size range; they obtained sinking rates of $0.24,1.54$ and $2.32 \mathrm{~m} \mathrm{~d}^{-1}$ for each category (calculated as ratio of experimentally observed flux to concentration). According to their data, the ratio of total flux to total concentration of particles larger than $1 \mu \mathrm{m}$ is $0.6 \mathrm{~m} \mathrm{~d}^{-1}$. The average sinking velocity with regard to total POC concentration could vary with location, season and other environmental conditions; hence no generalization is possible. We tentatively assume $1 \mathrm{~m} \mathrm{~d}^{-1}$ as maximum average for particles obtained from 5-l aliquots of Van Dorn samples filtered through a glass-fiber filter, so that the POC values obtained are nearly identical numerically with the maximum flux estimate in the water column.

If the above assumption is correct, direct observations of vertical flux of organic carbon as obtained by PC are 1-21 fold larger than conventional flux estimates based on observed particle concentrations (Tables 2 and 3). The pigment fluxes obtained by PC are one order of magnitude higher than fluxes estimated from concentrations in Van Dorn samples. These observations strongly suggest that the vertical flux is quite different from the conventional estimation based on a series of 'snapshot' samples limited in volume (Bishop et al., 1977).

A few authors noticed that a more or less marked intermediate POC minimum usually occurs somewhat below the euphotic layer in various regions of the Pacific and the Indian Ocean (Newell and Kerr, 1968; Nakajima, 1969, 1973; Ichikawa and Nishizawa, 1975). The minima were often the lowest values recorded in the entire water columns. In view of the extensive POC data collected by the workers cited above, this phenomenon - although little interpreted so far seems to be universal in occurrence; it is very noticeable in eutrophic regions but only barely recognizable in tropical oligotrophic areas. The situation seems to indicate that the event in the deep water region is not a simple continuation of the surface event as suggested by Newell and Kerr (1968). The vertical POC profile obtained during the cruise of KT-78-7 (Fig. 4) shows that a few anomalously low values of $10-20 \mathrm{mg} \mathrm{C} \mathrm{m}$ ' appeared in the depth range $100-200 \mathrm{~m}$. However, the vertical flux variation observed demonstrates that the maximum abundant of particles actually sink through this intermediate minimum layer, in which POC is very scarce. Thus, the apparent universal occurrence of the minimum POC layer simply reflects the actual decrease in POC in that layer; a significant fraction of 
POC is already transformed into much larger pellets and sinks down rapidly through this layer escapıng from entrapment into a snapshot type water sampler

This marked contrast between flux profile and concentration profile is considered to be due to differences in collecting efficiencies of the 2 sampler systoms which give distinctive differences in the size spectra obtained. Conventional snapshot samples tend to collect particles less than $10^{2} \mu \mathrm{m}$ in diameter which or ur homogeneously and constitute the background concentrations' (Wangersky, 1974). Most size-distribution data obtained with the electronic counting method represent only background particles (Sheldon and Parsons, 1967; Sheldon et al., 1972). PC, however, effectively collects particles in the size range well above ca $10^{2} \mu \mathrm{m}$ (Fig. 7), i. e. the predominant components of the material downward transfer, due to their rapid sinking velocities and large sizes. When some large particles are caught by chance in a Van Dorn type sampler, an anomalously high value of $\mathrm{POC}$ is obtained against the smooth background profile, and the anomalous value is often discarded as a contaminant. There is also a very good possibility that the large particles caught in a Van Dorn type sampler easily escape from final quantitative analysis of POC (Gardner, 1977). Iseki (1977) presented a theoretical analysis of the chance of large-particle occurrence in a limited volume of sample water, and has shown that hundreds of liters of a water are needed for obtaining a single particle of about $1 \mathrm{~mm}$.

Only a small amount of sinking particles was found in PC at deeper layers $(300,400$ and $500 \mathrm{~m}$ ). Several hypotheses can be advanced to explain the sharp decrease of downward flux in these layers: (1) The contents of large particles when damaged either

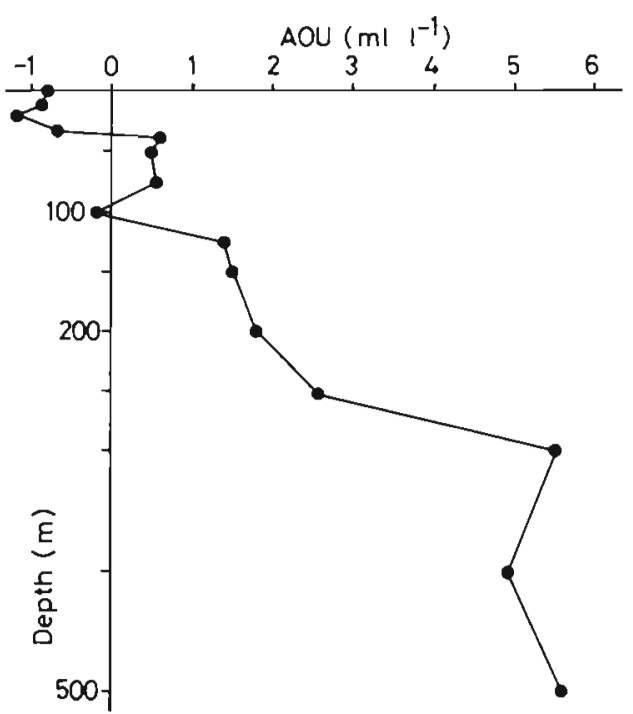

Fig. 9. Vertical variation of apparent oxygen utulization (AOU) observed at Station 78-1

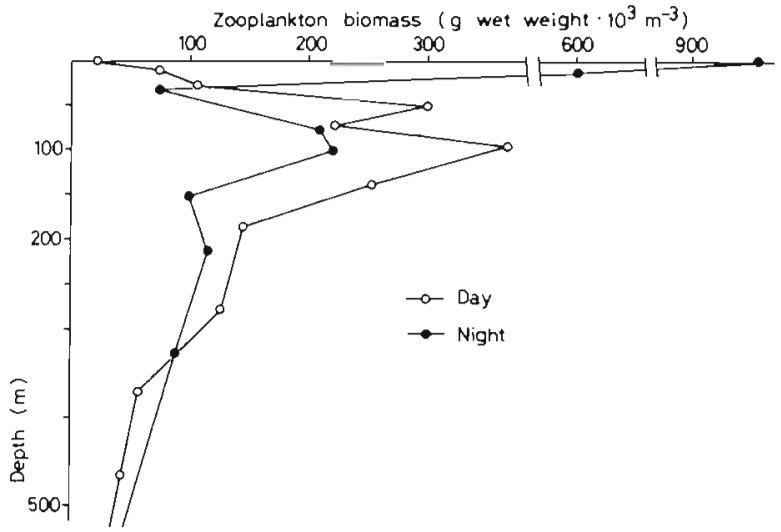

Fig. 10. Vertical distribution of zooplankton biomass collected with MTD nets (Motoda Simultaneous Horizontal Tow Nets) at Station 78-1

mechanically or biologically will disperse out into seawater forming patches of slow sinking particles. However, this is not a satisfactory explanation in this case because no marked increase in POC was observed in the same depth range (Fig. 4). (2) The sinking large particles are attacked by bacterial populations. The vertical variation of AOU (apparent oxygen utilization, Redfield et al., 1963) at St. 78-1 is shown in Fig. 9. The distribution of points in this figure shows a marked increase of AOU at 250-300 m; here the vertical flux of organic particles decreased sharply indicating that a significant amount of the oxidizable fractions actually decomposes in these layers. (3) The particles are ingested by coprophagous zooplankters. Evidence for coprophagy by bathypelagic copepods has been presented by Frankenberg and Smith (1967), Johannes and Satomi (1966), Paffenhöfer and Knowls (1979). The similarity of zooplankton profiles (Fig. 10) with the profile of vertical fluxes may indicate that fecal materials are produced and consumed concurrently, although intra- and interspecific relations in the production and consumption of fecal materials are not known. (4) The particles are consumed by predacious animals and converted into still larger pellets that can scarcely be caught by the PC. Mauchline (1972) suggested for the bathypelagic zone of the ocean that the size of planktonic organisms increased with depth, leading to a concurrent increase in the size of fecal pellets. If this is so, the $\mathrm{PC}$ would probably have missed most of these large pellets, primarily due to the inadequate collection area $\left(154 \mathrm{~cm}^{2}\right)$.

A simple model of transport of organic particles in the upper $500 \mathrm{~m}$ water layer can be outlined as follows (cf. Fig. 8). Organic particles are produced in the form of phytoplankters in the depth range $0-50 \mathrm{~m}$. Most of the phytoplankton production is grazed by zooplankton, and about $30 \%$ of the ingested material is aggregated into fecal pellets (Steele, 1974). Fecal particles 
sink down and are re-utilized by animals producing new fecal pellets or else degraded to slow sinking particles before they arrive at a depth of $500 \mathrm{~m}$. However, the fact that the observed organic carbon flux is higher than the background concentration of POC times the maximal average sinking velocity $\left(1 \mathrm{~m} \mathrm{~d}^{-1}\right)$ of these particles and contains some fresh fecal material, suggests that there is a significant downward flux of rapidly sinking particles at these deepest layers studied. The estimated productivity in the Oyashio region is $1.51 \mathrm{~g} \mathrm{C} \mathrm{m}^{-2} \mathrm{~d}^{-1}$ in spring (Taniguchi and Kawamura, 1972). If the model is correct, approximately $28 \%$ of the daily production of organic carbon sinks down as daily particulate flux $\left(418 \mathrm{mg} \mathrm{C} \mathrm{m}^{-2} \mathrm{~d}^{-1}\right)$ and $93 \%$ of the flux is transformed into any of the forms not effectively caught by the PC within the $500 \mathrm{~m}$ water column. It is clear that the main process in the transport of material from the euphotic layer through the water column below is the sinking of larger particles' consisting mostly of fecal materials produced by animal plankters, but not of the minute phytoplankton themselves.

Acknowledgements. We wish to thank Dr A. Taniguchi for helpful suggestions concerning our manuscript. We also thank officers and crew of R. V 'Tansei Maru', Ocean Research Institute, University of Tokyo. Gratitude is further expressed to Miss L. K. Miyake for correcting our English manuscript.

\section{LITERATURE CITED}

Bader, H. (1970). The hyperbolic distribution of particle sizes. J. geophy. Res. 75: 2822-2830

Bishop, J. K. B., Edmond, J. M., Ketten, D. R., Bacon, M. P., Silker, W B. (1977). The chemistry, biology and vertical flux of particulate matter from the upper $400 \mathrm{~m}$ of the equatorial Atlantic Ocean. Deep Sea Res. 24: 511-548

Burns, N. M., Rosa, F. (1980). In situ measurement of settling velocity of organic carbon particles and 10 species of phytoplankton. Limnol. Oceanogr. 25: 855-864

Ferrante, J. G., Parker, J. I. (1977). Transport of diatom frustules by copepod fecal pellets to the sediments of lake Michigan. Limnol. Oceanogr. 22: 92-98

Fowler, S. W., Small, L. F. (1972). Sinking rates of euphausiid fecal pellets. Limnol. Oceanogr. 17: 293-296

Frankenberg, D., Smith, L. F. (1967). Coprophagy in marine animals. Limnol. Oceanogr. 12: 443-450

Gardner, W D. (1977). Incomplete extraction of rapidly setthing particles from water samplers. Limnol. Oceanogr. 22: $764-767$

Gordon, D. C. (1970). Some studies on the distribution and composition of particulate organic carbon in the North Atlantic Ocean. Deep Sea Res. 17: 233-243

Hakanson, L. (1976). A bottom sediment trap for recent sedimentary deposits. Limnol. Oceanogr 21: 170-174

Honjo, S. (1976). Coccoliths: Production, transportation and sedimentation. Mar Micropaleo. 1: 65-79

Honjo, S. (1978). Sedimentation of materials in the Sargasso Sea at a 5,367 m deep station. J. mar. Res. 36:469-492
Honjo, S., Roman, M. R. (1978). Marine copepod fecal pellets Production, preservation and sedimentation. J. mar Res 36: $45-57$

Ichikawa, T., Nishizawa, S. (1975). Particulate organıc carbon and nitrogen in the Eastern Pacific Ocean. Mar Biol. 29: $129-138$

Iseki, K. (1977). A study of vertical transport system of particulate organic matter in the sea. Ph. D. thesis, Tohoku University

Johannes, R. E., Satomi, M. (1966). Composition and nutritive value of fecal pellets of a marine crustacean. Limnol. Oceanogr. 11: 191-197

Kawai, H. (1955). On the polar frontal zone and its fluctuation in the waters to the northeast of Japan (II). Bull. Tohoku Reg. Fish. Res. Lab. 5: 1-42

Kimmel, B. L., Axler, R. P., Goldman, C. R. (1977). A closing replicate-sample, sediment trap. Limnol. Oceanogr 22: $768-772$

Kirchner, W B. (1975). An evaluation of sediment trap methodology. Limnol. Oceanogr 20:657-660

Mauchline, J. (1972). The biology of bathypelagic organısms, especially Crustacea. Deep Sea Res. 19: 753-780

McCave, I. N. (1975). Vertical flux of particles in the ocean. Deep Sea Res. 22: 491-502

Menzel, D. W., Goering, J. J. (1966). The distribution of organic detritus in the ocean. Limnol. Oceanogr 11: 333-3.37

Menzel, D. W. (1967). Particulate organic carbon in the deep sea. Deep Sea Res. 14: 229-238

Motoda, S. (1971). Devices of simple plankton apparatus $V$ Bull. Fac. Fish. Hokkaido Univ. 22: 101-106

Nakajima, K. (1969). Suspended particulate matter in the waters on both sides of the Aleutian Ridge. J. oceanogr Soc. Japan 25: 239-248

Nakajima, K. (1973). Suspended particulate matter in western north Pacific Ocean. Mem. Fac. Fish. Hokkaido Univ. 20: $1-106$

Newell, B. S., Kerr, J. D. (1968). Suspended organic matter in the south-eastern Indian Ocean. Aust. J mar Freshwat. Res. 19: 129-138

Nishizawa, S. (1966). Suspended material in the sed: From detritus to symbiotic microcosmos. Inf. Bull. Planktol. Japan 13:1-33

Nishizawa. S. (1969). Suspended material in the sea. 11. Reevaluation of the hypotheses. Bull. Plankton Soc Japan 16: $1-42$

Nishizawa, S., Taniguchı, A., [chikawa, T (1971). An oceanographic section from Lat. $20^{\circ} \mathrm{S}$ to $20^{\circ} \mathrm{N}$ at $175 \mathrm{E}$ in July to August. Kaiyo Rep 3:1-16

Paffenhöfer, G. A., Knowls, S. C. (1979). Ecological implica. tions of fecal pellet size, production and consumption by copepods. J. mar Res. 37. 3.5-49

Parsons, T R. (1963). Suspended organic matter in sed water Progr Oceanogr 1: 203-239

Redfield, A. C., Ketchum, B. H., Rtchards, F. A. (196.3) The influence of organisms on the composition of seawater. In: Hill, M. N. (ed.) The sea, Vol. 2. Wiley-Interscience, New York, pp. 26-27

Riley, G. A., Van Hemart, D., Wangersky, P. J. (1965) Organic aggregates in surface and deep waters of the Sargasso Sea. Limnol. Oceanogr 10:354-363

Riley, G. A. (1970). Particulate organic matter in sea water Adv. mar Biol. 8: 1-118

Schrader, H. J. (1971). Fecal pellets: role in sedimentation of pelagic diatoms. Science, N. Y 174:55-57

Sheldon, R. W., Parsons, T R. (1967). A continuous size 
spectrum for particulate matter in the sea. J. Fish. Res. Bd Can. 24: 909-915

Sheldon, R. W., Prakash, A., Sutcliffe, W H. (1972). The size distribution of particles in the ocean. Limnol. Oceanogr. 17: $327-340$

Smayda, T J. (1969). Some measurements of the sinking rate of fecal pellets. Limnol, Oceanogr 14:621-625

Smayda, T. J. (1970). The suspension and sinking of phytoplankton in the sea. Oceanogr mar Biol. A. Rev. 8: $353-414$

Staresinic, N., Rowe, G. T., Shaughnessey, D., Williams III, A. J. (1978). Measurement of the vertical flux of particulate organic matter with a free-drifting sediment trap. Limnol. Oceanogr 23: 559-562
Steele, J. H. (1974). The structure of marine ecosystems, Harvard Univ. Press, Cambridge, Mass

Strickland, J. D. H., Parsons, T R. (1968). A practical handbook of seawater analysis. Fish. Res. Bd Can. Bull. 167

Taniguchi, A., Kawamura, T (1972). Primary production in the Oyashio region with special reference to the subsurface chlorophyll maximum layer and the phytoplanktonzooplankton relationships. In: Takenouchi et al. (eds.) Biological oceanography of the northern North Pacific Ocean. Idemitsu, Tokyo, pp. 231-243

Wangersky, P. J. (1974). Particulate organic carbon: sampling variability. Limnol. Oceanogr 19: 980-984

Wiebe, P. H., Boyd, S. H., Winget, C. (1976). Particulate matter sinking to the deep-sea floor at $2,000 \mathrm{~m}$ in the tongue of the ocean, Bahamas with a description of a new sedimentation trap. J. mar. Res. 34: 341-353

This paper was presented by Professor M. Anraku; it was accepted for printing on July 20, 1981 